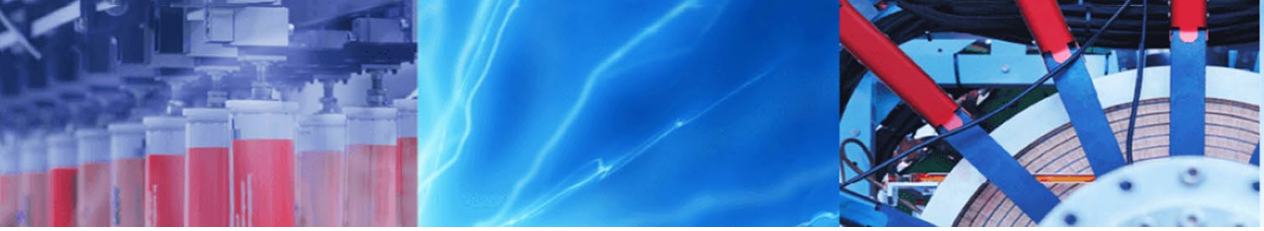

Research Article

\title{
Evaluation of chipping and impregnation of Scots pine heartwood with sulfite cooking liquor
}

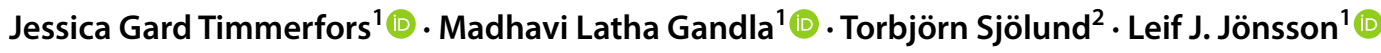

Received: 18 August 2020 / Accepted: 6 November 2020 / Published online: 17 November 2020

(C) The Author(s) $2020 \quad$ OPEN

\begin{abstract}
Heartwood and sapwood of Scots pine were procured and chipped using a newly developed pilot drum chipper, which for the heartwood resulted in a combined fraction of pin chips and fines of $\sim 3 \%$. Heartwood wood chips were processed using a set of 15 different reaction conditions that differed with respect to impregnation and cooking procedures. The result was evaluated with regard to absorption of impregnation liquid, pulp yield, fraction of reject, viscosity, kappa number, brightness, fiber properties, and chemical composition measured using two different techniques (compositional analysis using two-step hydrolysis with sulfuric acid and Py-GC/MS). The chemical analyses provided detailed information about how all main organic constituents of the wood, cellulose, hemicelluloses, and lignin, were affected by operational parameters. Inclusion of a pressurized ( 9 bar) impregnation step resulted in a more efficient cook, but the duration of the impregnation step (five minutes and four hours were compared) was not decisive for the outcome. Omission of the impregnation step or using low-pressure impregnation resulted in high fractions of reject, poor delignification, and, with a cooking time of two hours, no advantages with regard to fiber length and fraction of fines. The results indicate that the conditions used during impregnation, such as pressure, temperature, and acidity of impregnation liquid, warrant further attention in future studies.
\end{abstract}

Keywords Drum chipper $\cdot$ Cellulose $\cdot$ Impregnation $\cdot$ Heartwood $\cdot$ Scots pine $\cdot$ Sulfite cooking

\section{Introduction}

The sulfite process has been of considerable interest for the development of forest-based biorefineries, where one possible product is dissolving pulp that can be utilized for textile production and production of cellulose derivatives. Even though the production of dissolving pulp peaked in 1975 , the demand has typically increased since 2000 . Thus, the global production, 4.5 million metric tons in 2010, was lower than the 5.3 million metric tons in 1975, but higher than the 2.3 million metric tons in 2000 [1]. The increase is mostly due to an increasing demand for highly pure cellulose fibers for textile applications, but also for manufacture of cellulose acetate for high value-added films, plastics, and coatings, cellulose ethers, and cellulose powder [2]. Today, dissolving pulp is mainly produced by using the acid sulfite process, but in some cases, by using the Kraft process [3]. One advantage with the acid sulfite process is the high recovery rate for the cooking chemicals.

Sulfite cooking could be performed in different $\mathrm{pH}$ ranges: acidic, neutral, or alkaline. In the acid sulfite process, the active chemicals are sulfurous acid $\left(\mathrm{H}_{2} \mathrm{SO}_{3}\right)$ and bisulfite ions $\left(\mathrm{HSO}_{3}{ }^{-}\right)$[4]. There could be a single-step reaction with low $\mathrm{pH}$ cooking $(\mathrm{pH}$ 1.5-2) or a two-step reaction based on bisulfite, where the first step is impregnation at a pH around 4, and the second step is more acidic [5]. The process could also be neutral or alkaline or include neutral or alkaline steps $[5,6]$.

$\triangle$ Jessica Gard Timmerfors, jessica.gard.timmerfors@umu.se| ${ }^{1}$ Department of Chemistry, Umeå University, 90187 Umeå, Sweden. ${ }^{2}$ MoRe Research I Örnsköldsvik AB, Box 70, 89122 Örnsköldsvik, Sweden. 
Softwood is the main raw material for dissolving pulps, but hardwood is also used [1]. In Nordic countries, the use of softwood, particularly Norway spruce, is predominant with regard to the sulfite process. The forest resources in Sweden are mainly Norway spruce $(40.4 \%$ of the standing volume) and Scots pine (39.3\%) [7].

Although Scots pine is abundant, extensive utilization of pine in acidic sulfite processes is challenging. This is due to the occurrence of stilbenes, which are common wood extractives in the heartwood of pine. The stilbenes include pinosylvins, such as pinosylvin and pinosylvin monomethyl ether. Stilbenes are responsible for the darkening of wood that becomes exposed and cause problems during acidic pulping [8]. The pinosylvins, which are phenols, are involved in condensation reactions with reactive lignin moieties during acidic process conditions [8]. The heartwood of Scots pine typically contains high concentrations of pinosylvin and pinosylvin monomethyl ether, which results in lower sulfonation of lignin, which in turn makes the lignin less solvable [4]. Even low concentrations of pinosylvins inhibit delignification during sulfite pulping [8], which may result in a black cook. The sapwood contains less pinosylvins. Impregnation of heartwood is known to be much more difficult than impregnation of sapwood [5]. Thus, impregnation and cooking of pine heartwood is a problem in sulfite pulping under acidic conditions. If this problem can be overcome, pine can be used more extensively in the future than today.

The wood chips that enter digesters must have a certain quality to assure smooth operation and low quantities of reject after cooking. This is true regardless of whether it is a sulfite process or a Kraft process, and regardless of whether it is heartwood or sapwood. To get smooth operation and high pulp yields, it is important to have a homogenous feedstock with large fractions of accept chips and small fractions of fines and pin chips. A new wood-chipping technology based on drum chippers has already shown promising results with regard to producing wood chips for the sulfite process [9].

The aim of this study was to investigate preparation of wood chips from Scots pine and utilization of wood chips originating from heartwood in an acidic sulfite process. The strategy used to obtain heartwood wood chips was to separate heartwood and sapwood before chipping and utilize the new state-of-the-art drum-chipping technology [9] to process the wood. Both heartwood and sapwood were chipped, but, as there are little or no problems associated with impregnation and cooking of sapwood, only the heartwood wood chips were studied in the subsequent impregnation and cooking experiments. Impregnation and cooking of the heartwood was investigated using 15 different experimental conditions, based on five different impregnation scenarios (including a control processed without any separate impregnation step) and three different cooking times for each impregnation scenario. The impregnation process was varied with regard to pressure, time, and impregnation liquid. The uptake of impregnation liquid was studied in a specially-designed impregnation reactor. Cooking was always performed using the same cooking liquid and the same temperature, but for one, two, or four hours. The different processing conditions were compared by analysis of pulp yield, formation of reject, pulp properties, fiber properties, and changes in chemical composition. Thus, the investigation covered separation and chipping of heartwood and sapwood from Scots pine, analysis of wood characteristics and chipping results, impregnation and cooking of heartwood wood chips, and analysis of the processed materials. Research in this area can contribute to more efficient forestindustrial biorefineries and to a better understanding of process conditions that result in superior pulp yield and quality.

\section{Experimental}

\subsection{Wood characteristics and chipping}

\subsubsection{Wood logs}

Two Scots pine (Pinus sylvestris L.) trees were harvested during late summer west of Örnsköldsvik $\left(63^{\circ} 17^{\prime} 27^{\prime \prime} \mathrm{N}\right.$, $18^{\circ} 42^{\prime} 56^{\prime \prime}$ E), Sweden. Four wood logs with diameters in the range $10-14 \mathrm{~cm}$ were produced from the trees. The logs were debarked manually. The heartwood was separated from the sapwood using a chain saw. In this way, each log was divided into five portions, four thinner outer portions consisting of sapwood and one thicker inner portion consisting of heartwood.

\subsubsection{Wood chipping}

The heartwood and the sapwood pieces were chipped separately using a pilot-scale drum chipper of novel design. The pilot-scale drum chipper, which was constructed by Multi Channel Sweden AB (Bredbyn, Sweden), had a drum with a diameter of $3 \mathrm{~m}$ and a width of $20 \mathrm{~cm}$, and was equipped with 16 knives [9]. The knife angles $\left(\alpha=2.2^{\circ}\right.$ and $\left.\varepsilon^{\prime}=30^{\circ},[9]\right)$ and the $T$ dimension were adjusted to be suitable for production of wood chips with an average length of around $25 \mathrm{~mm}$. The drum velocity was $30 \mathrm{~m} \mathrm{~s}^{-1}$. Samples were collected in $125 \mathrm{~L}$ plastic bags and were stored refrigerated. 


\subsubsection{Characterization, drying, and screening of wood chips}

For each of heartwood and sapwood, the wood chip samples were mixed and downsized according to SCAN-CM 41:94 (sampling) (Scandinavian Pulp, Paper and Board Testing Committee, Stockholm, Sweden) into five $10 \mathrm{~L}$ portions and one $40-50 \mathrm{~L}$ portion. The $40-50 \mathrm{~L}$ portions were analyzed using a ScanChip image analysis system (PulpEye, Örnsköldsvik, Sweden) located in the Metsä Board Husum mill (Husum, Sweden). Three of the 10-L portions were analyzed according to SCAN-CM 47:92 (thickness and thickness distribution). All five 10-L portions were analyzed using SCAN-CM 40:01 (size distribution), and the accept fractions (large and small accept as defined in Table 1) were collected and pooled to one sample whereas the other fractions were discarded after quantification. The dry-matter content of the accept fractions was determined, using quintuple sampling, according to SCANCM 39:94 (dry-matter content) and were then stored in a freezer. Two samples, each with a volume of $0.1-0.3 \mathrm{~L}$, were collected from the accept chips. Of these, the first sample was freeze-dried for analysis of extractives. The second sample was dried in an oven at $50^{\circ} \mathrm{C}$ for $48 \mathrm{~h}$ and then debarked using a scalpel to remove any leftover bark. The wood chips were then milled to rough powder using an IKA A11 Basic Analytical Mill (IKA, Staufen. Germany) and sieved using 100-500 $\mu \mathrm{m}$ sieves (Retsch Analytical AS 200, Haan, Germany). The moisture content was measured by using an HG63 moisture analyzer (Mettler-Toledo, Greifensee, Switzerland). The wood that was sieved to a particle size of 100-500 $\mu \mathrm{m}$ was used for compositional analysis, i.e. analysis of carbohydrates, Klason lignin, and ASL. In addition, a minor fraction of the sieved wood was ball-milled (Retsch MM 400) to a fine powder according to the procedure described by Gandla et al. [10] and used for Py-GC/MS and ash analysis.

\subsection{Impregnation}

Portions consisting of $500 \mathrm{~g} \mathrm{DW}$ (dry weight) wood chips were weighed in, and residual bark and wood chips with knots were removed. Each portion was then investigated using a pilot-scale impregnation reactor. The pilot impregnation reactor was a further development of a reactor that was previously used in studies of impregnation of wood chips for Kraft pulping [11, 12]. The reactor is equipped with a sensor allowing continuous gravimetric measurements to assess the uptake of impregnation liquid by wood chips positioned in a basket in the interior of the reactor. The reactor was connected to a system with existing chemical tanks and a pilot digester at MoRe Research (Örnsköldsvik, Sweden). After modification, the
Table 1 Data for wood chips produced from heartwood and sapwood. ${ }^{\mathrm{a}}$

\begin{tabular}{|c|c|c|c|c|}
\hline Parameter/fraction & Def. $^{b}$ & Heartwood & Sapwood & $\overline{\text { Significance }^{c}}$ \\
\hline \multicolumn{5}{|l|}{ SCAN standard ${ }^{d}$} \\
\hline Dry matter (\%) & & $57.4 \pm 1.3$ & $39.6 \pm 0.1$ & Yes*** \\
\hline Thickness (mm) & & $6.4 \pm 0.2$ & $5.3 \pm 0.1$ & Yes $^{* * *}$ \\
\hline Oversized (\%) & $>\varnothing 45$ & $3.0 \pm 1.1$ & $3.1 \pm 0.7$ & No \\
\hline Overthick (\%) & $>/ / 8$ & $18.6 \pm 2.1$ & $11.8 \pm 2.4$ & Yes $^{* * *}$ \\
\hline Large accept (\%) & $>\varnothing 13$ & $61.7 \pm 2.1$ & $55.4 \pm 1.5$ & Yes $^{* * *}$ \\
\hline Small accept (\%) & $>\varnothing 7$ & $13.4 \pm 1.2$ & $22.8 \pm 1.8$ & Yes*** \\
\hline Pin chips (\%) & $>\varnothing 3$ & $2.9 \pm 0.4$ & $6.0 \pm 1.4$ & Yes $^{* * *}$ \\
\hline Fines (\%) & $<\varnothing 3$ & $0.3 \pm 0.1$ & $0.9 \pm 0.3$ & Yes $^{* * *}$ \\
\hline Total accept ${ }^{\mathrm{e}}(\%)$ & & $75.2 \pm 2.2$ & $78.2 \pm 1.9$ & Yes** \\
\hline \multicolumn{5}{|l|}{ ScanChip analyzere } \\
\hline Valid percentage ${ }^{f}$ & & 55.1 & 35.9 & - \\
\hline Length $^{g}(\mathrm{~mm})$ & & 23.4 & 22.1 & - \\
\hline Width $^{g}(\mathrm{~mm})$ & & 23.7 & 17.7 & - \\
\hline Thickness $^{g}(\mathrm{~mm})$ & & 5.1 & 4.2 & - \\
\hline Oversized (\%) & $>\varnothing 45$ & 1.6 & 0.6 & - \\
\hline Overthick (\%) & $>/ / 8$ & 18.3 & 8.0 & - \\
\hline Large accept (\%) & $>\varnothing 13$ & 66.4 & 53.3 & - \\
\hline Small accept (\%) & $>\varnothing 7$ & 10.8 & 28.2 & - \\
\hline Pin chips (\%) & $>\varnothing 3$ & 2.7 & 9.0 & - \\
\hline Fines (\%) & $<\varnothing 3$ & 0.2 & 0.9 & - \\
\hline Total accept ${ }^{\mathrm{e}}(\%)$ & & 77.2 & 81.5 & - \\
\hline \multicolumn{5}{|l|}{ Extractives $^{h}$} \\
\hline Pinosylvin (mg/kg) & & 210 & 54 & - \\
\hline $\begin{array}{l}\text { Pinosylvin mono- } \\
\text { methyl ether } \\
(\mathrm{mg} / \mathrm{kg})\end{array}$ & & 352 & 158 & - \\
\hline Acetone extract (\%) & & 7.1 & 2.4 & - \\
\hline
\end{tabular}

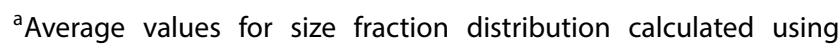
SCAN-CM 40:01 or using automated chip analyzer

${ }^{\mathrm{b}}$ Definition: $\varnothing$, screen hole diameter in $\mathrm{mm}$; //, screen slot distance in $\mathrm{mm}$

'Significant differences ( $t$-test): No $=P>0.1$, Yes $=P \leq 0.1$ (with level of significance indicated: *** $p \leq 0.01$; ${ }^{* *} 0.01<p \leq 0.05$; * $0.05<p \leq 0.1)$

${ }^{d}$ Calculation of average values: dryness, SCAN 46:92; bulk density, SCAN-CM 46:92; thickness distribution, SCAN-CM 47:92

eSum of large and small accept chips

fLength, thickness, and width are determined for the fraction of material that is defined as wood chips, The chips need to have two cut edges, and have a shape that is close to symmetrical. Wood chips that are too big (outside the measured intervals) or too small, too asymmetrical, and fines are not defined as valid

${ }^{g}$ Average values for length, thickness, and width calculated using automated chip analyzer

${ }^{\mathrm{h}}$ Fractions in percent based on dry weight

reactor was adapted for studies of both alkaline and acidic impregnation liquids, the liquid could be heated during impregnation by using a heat exchanger, and the lid 
cooling system was extended to make it possible to handle reactions performed at higher temperatures.

The basket was loaded with wood chips, and preheated $\left(80^{\circ} \mathrm{C}\right)$ impregnation liquid containing roughly $2.5 \%$ bound and $5 \%$ total sulfur dioxide was added (Table 2 ). The impregnation liquid ( $25 \mathrm{~L}$ for each run) that was used for most experimental series was prepared the day before use by dissolving $820 \mathrm{~g}$ of sodium hydroxide in $24.2 \mathrm{~kg}$ of deionized water. Sulfur dioxide was then bubbled through the liquid until $\mathrm{pH} 4.0$ was reached. The fractions of bound and total sulfur dioxide were determined through titration with solutions of potassium iodate and sodium thiosulfate. These fractions, which were determined just before the impregnation liquid was added to a chemical tank for heating, are presented in Table 2. A fraction ( $16 \mathrm{~L}$ ) of the pre-heated impregnation liquid was added from the tank to the impregnation reactor so that the basket with its content was fully covered by the liquid. The temperature of the pre-heated liquid first decreased to $45^{\circ} \mathrm{C}$ due to dissipation of heat. The heating started and the temperature of the liquid was increased from $45^{\circ} \mathrm{C}$ to $90^{\circ} \mathrm{C}$ in five min. The pressure was set by pumping nitrogen gas into the reactor. Two different pressures were used in the impregnation studies (Table 2). The duration of the impregnation was four hours, as measured from the start of the addition of the liquid to the removal of liquid, or five min, as measured from the beginning until the end of pressurization (the heating time). For further information about experimental conditions, see Table 2.

One impregnation was made with cooking liquid. As the cooking liquid was more acidic than the impregnation liquid, this sample was labeled "Acid" (Table 2). Cooking liquid was prepared the day before by first dissolving $94 \mathrm{~g}$ of sodium hydroxide in $4600 \mathrm{~g}$ of deionized water and then bubbling sulfur dioxide through the liquid until the $\mathrm{pH}$ was around 1.4. The fractions of bound and total sulfur dioxide were determined and air or further sulfur dioxide was bubbled through the liquid until the fractions of bound and total sulfur dioxide reached approx. $1.5 \%$ and $8 \%$, respectively. The fractions of bound and total sulfur

Table 2 Impregnation and cooking conditions

\begin{tabular}{|c|c|c|c|c|c|c|c|c|}
\hline \multirow{3}{*}{ Designation $^{\mathrm{a}}$} & \multicolumn{4}{|c|}{ Impregnation in impregnation reactor } & \multicolumn{4}{|l|}{ Sulfite cooking } \\
\hline & \multirow[t]{2}{*}{ Time } & \multirow{2}{*}{$\begin{array}{l}\mathrm{SO}_{2} \text { fraction in } \\
\text { imp. liq. }{ }^{\mathrm{b}}(\%)\end{array}$} & \multirow[t]{2}{*}{ Pressure $(\mathrm{bar})^{\mathrm{c}}$} & \multirow{2}{*}{$\begin{array}{l}\text { Absorbed } \\
\text { imp. liq. }{ }^{d}(g)\end{array}$} & \multirow{2}{*}{$\begin{array}{l}\text { Added cook- } \\
\text { ing liq. }{ }^{\mathrm{e}}(\mathrm{mL})\end{array}$} & \multirow{2}{*}{$\begin{array}{l}\text { Cooking } \\
\text { time }(\mathrm{h})\end{array}$} & \multicolumn{2}{|c|}{$\mathrm{SO}_{2}$ fraction in cooking liq. ${ }^{\mathrm{f}}(\%)$} \\
\hline & & & & & & & $\begin{array}{l}\text { Before } \\
\text { preparation }\end{array}$ & After preparation \\
\hline $\mathrm{IOC} 1 \mathrm{~h}$ & - & - & - & 0 & 365 & 1 & $1.6 / 8.0$ & $1.6 / 7.3$ \\
\hline $10 C 2 h$ & - & - & - & 0 & 365 & 2 & $1.6 / 8.0$ & $1.6 / 7.3$ \\
\hline $10 C 4 h$ & - & - & - & 0 & 365 & 4 & $1.6 / 8.0$ & $1.6 / 7.3$ \\
\hline $15 \mathrm{mC} 1 \mathrm{hLP}$ & $5^{\prime}$ & $2.6 / 5.0$ & $1-2$ & 550 & 325 & 1 & $1.7 / 8.2$ & $1.8 / 8.0$ \\
\hline $15 \mathrm{mC} 2 \mathrm{hLP}$ & $5^{\prime}$ & $2.6 / 5.0$ & $1-2$ & 550 & 325 & 2 & $1.7 / 8.2$ & $1.8 / 8.0$ \\
\hline $15 \mathrm{mC} 4 \mathrm{hLP}$ & $5^{\prime}$ & $2.6 / 5.0$ & $1-2$ & 550 & 325 & 4 & $1.7 / 8.2$ & $1.8 / 8.0$ \\
\hline $15 \mathrm{mC} 1 \mathrm{~h}$ & $5^{\prime}$ & $2.8 / 5.1$ & 9 & 797 & 285 & 1 & $1.8 / 8.1$ & $1.7 / 7.6$ \\
\hline $15 \mathrm{mC} 2 \mathrm{~h}$ & $5^{\prime}$ & $2.8 / 5.1$ & 9 & 797 & 285 & 2 & $1.8 / 8.1$ & $1.7 / 7.6$ \\
\hline $15 \mathrm{mC} 4 \mathrm{~h}$ & $5^{\prime}$ & $2.8 / 5.1$ & 9 & 797 & 285 & 4 & $1.8 / 8.1$ & $1.7 / 7.6$ \\
\hline $14 \mathrm{hC} 1 \mathrm{~h}$ & $4 \mathrm{~h}$ & $2.7 / 5.0$ & 9 & 1006 & 230 & 1 & $1.8 / 8.1$ & $1.8 / 7.9$ \\
\hline $14 \mathrm{hC} 2 \mathrm{~h}$ & $4 \mathrm{~h}$ & $2.7 / 5.0$ & 9 & 1006 & 230 & 2 & $1.8 / 8.1$ & $1.8 / 7.9$ \\
\hline $14 \mathrm{hC} 4 \mathrm{~h}$ & $4 \mathrm{~h}$ & $2.7 / 5.0$ & 9 & 1006 & 230 & 4 & $1.8 / 8.1$ & $1.8 / 7.9$ \\
\hline I4hC1hAcid & $4 \mathrm{~h}$ & $1.6 / 8.0$ & 9 & 920 & 247 & 1 & $1.6 / 8.0$ & $1.6 / 7.3$ \\
\hline $14 \mathrm{hC} 2 \mathrm{hAcid}$ & $4 \mathrm{~h}$ & $1.6 / 8.0$ & 9 & 920 & 247 & 2 & $1.6 / 8.0$ & $1.6 / 7.3$ \\
\hline I4hC4hAcid & $4 \mathrm{~h}$ & $1.6 / 8.0$ & 9 & 920 & 247 & 4 & $1.6 / 8.0$ & $1.6 / 7.3$ \\
\hline
\end{tabular}

a - Impregnation time [0, 5 min (5'), or 4 h]; C-Cooking conditions [time ( $1 \mathrm{~h}, 2 \mathrm{~h}$, or $4 \mathrm{~h}$ ); LP (lower pressure, i.e. 1.4 bar rather than 9 bar)]; Acid-more acidic impregnation conditions

${ }^{\mathrm{b}}$ The fraction of $\mathrm{SO}_{2}$ is presented as $\mathrm{SO}_{2}$ bound $/ \mathrm{SO}_{2}$ total, as determined using titration

'The pressure was affected by the temperature, and the variation during impregnation was around 0.3 bar

${ }^{\mathrm{d}}$ The absorbed volume of impregnation liquid was determined by weighing the impregnated wood chips as soon as possible after they were removed from the reactor and subtracting the dry weight of the wood chips (500 $\mathrm{g}$ per reaction)

${ }^{e}$ Cooking liquid was added in a liquid-to-wood ratio of $5 \mathrm{l} / \mathrm{kg}$ DW wood chips (after adjusting the dosage depending on wood moisture content or content of impregnation liquid)

${ }^{\mathrm{f}}$ The fraction of $\mathrm{SO}_{2}$ is presented as $\mathrm{SO}_{2}$ bound/ $\mathrm{SO}_{2}$ total (in the liquid before it was added to the autoclave reactor and after pouring the liquid into the autoclave reactor). The amount was determined using titration 
dioxide were checked just before cooking, and, if needed, adjusted. The values are indicated in Table 2 .

After the end of the impregnation, the heat was turned off, the pressure was decreased, and the liquid was drained from the reactor. The reactor was opened, the basket was removed, the sample was taken out and weighed. The sulfite cooking commenced directly after the impregnation.

\subsection{Sulfite cooking}

Sulfite cooking of impregnated or non-impregnated wood chips (Table 2) was performed using autoclave reactors in the laboratory of MoRe Research. The cooking of the wood chips was made directly after impregnation to minimize vaporization of impregnating liquid. Five series of cooking experiments were performed, each time with six autoclave reactors. Cooking liquid was added according to the scheme in Table 2. There were two cooking reactions for each of the 15 conditions shown in Table 2. The liquid-towood ratio was $5 \mathrm{~L}$ cooking liquid per kg wood chips (DW). The polyethylene glycol bath was pre-heated to $150^{\circ} \mathrm{C}$, and that temperature was kept during cooking. Autoclave reactors were taken up from the polyethylene glycol bath after one, two, or four hours (Table 2), and put in a water bath for cooling. The autoclave reactors were opened to allow gas exchange, and were kept in the water bath for an additional time of $15 \mathrm{~min}$. Then, the pulp/woody materials in each reactor were transferred to separate baskets and washed with deionized water in room temperature for at least eight hours. This resulted in two baskets with washed pulp/woody material for each of the 15 experimental conditions (Table 2).

\subsection{Chemical composition}

\subsubsection{Preparation and analysis of the pulp/woody material}

For each set of conditions from the cooking series, the content of one of the baskets was used to determine the pulp yield by incubation of the pulp/woody material in an oven at $105^{\circ} \mathrm{C}$ for at least $16 \mathrm{~h}$ or until the mass was constant. Thereafter, the contents of the baskets were weighed for determination of the pulp yield.

The pulp/woody material was milled to rough powder using the IKA A11 Basic Analytical Mill, and sieved using 100-500 $\mu \mathrm{m}$ sieves (Retsch Analytical AS 200). The moisture content was measured by using an HG63 moisture analyzer (Mettler-Toledo, Greifensee, Switzerland). The sieved pulp/woody material of a particle size of 100-500 $\mu \mathrm{m}$ was used for compositional analysis. Pulp/ woody material milled with the Retsch MM 400 was used for Py-GC/MS (pyrolysis—gas chromatography/mass spectrometry) analysis.

The content of the second basket of each set of samples from the cooking series was used for determination of reject content, kappa number, viscosity, and brightness. Only samples from a cooking time of two and four hours were analyzed using these methods, as the material from a cooking time of one hour was not converted to pulp (Fig. 1).

The contents of the baskets were defibrated at $30,000 \mathrm{rpm}$ in a defibrator and the pulp was screened using a Somerville-type equipment (Lorentzen \& Wettre App. 134, Type 3-1, No 440, with a $0.15 \mathrm{~mm}$ screen plate). The screening was performed as described in the standard method T 275 (TAPPI, Atlanta, GA, USA), except that the entire mass of the pulp (the pulp derived from $80 \mathrm{~g}$ DW wood chips) was filtered through the screen plate. The screened pulp was centrifuged and dried in an oven at $40^{\circ} \mathrm{C}$ for $18-24 \mathrm{~h}$ and analyzed three times according to ISO 5351 (viscosity), ISO 302 (kappa number), and ISO 2470 (brightness) (MoRe Research). The method descriptions were followed except that some of the samples were kept in suspension in deionized water overnight before the analysis.

After drying at $40^{\circ} \mathrm{C}$, one $\mathrm{g}$ of each set of the pulp samples was first suspended in $200 \mathrm{~mL}$ deionized water, and then in $3 \mathrm{~L}$ deionized water. Thereafter, the pulp samples were analyzed with regard to fiber dimensions and fines content using a PulpEye fiber module according to ISO 16065-2 (fiber length), Fa 10.400 (MoRe Research), and Fa 10.401 (MoRe Research). The fiber module has high-resolution optics and identifies and analyzes each fiber particle in a diluted suspension.

The reject, i.e. the woody material that could not pass through a 0.15 screen plate, was dried at $105^{\circ} \mathrm{C}$ for at least $16 \mathrm{~h}$. The reject was then weighed and the fraction of reject was calculated on basis of the amount of pulp and the amount of wood chips.

\subsubsection{Chemical analysis of wood chips and pulp}

Analysis of wood extractives was made by MoRe Research using acetone extraction, gravimetric analysis, and GC-MS (gas chromatography-mass spectrometry). Wood chips (heartwood and sapwood) were freeze-dried and then milled. The wood powder was extracted with acetone and the extract was weighed. A fraction of the acetone extract was evaporated and derivatized using CTMS (chlorotrimethylsilane), BSTFA [N,O-bis(trimethylsilyl)trifluoroacetamide], and pyridine prior to analysis with GC-MS (using a 7890A/5975C system from Agilent Technologies, Santa Clara, CA) for determination of the contents of pinosylvin and pinosylvin monomethyl ether. 
Fig. 1 Images of pulps/woody materials after cooking and after drying at $105^{\circ} \mathrm{C}$

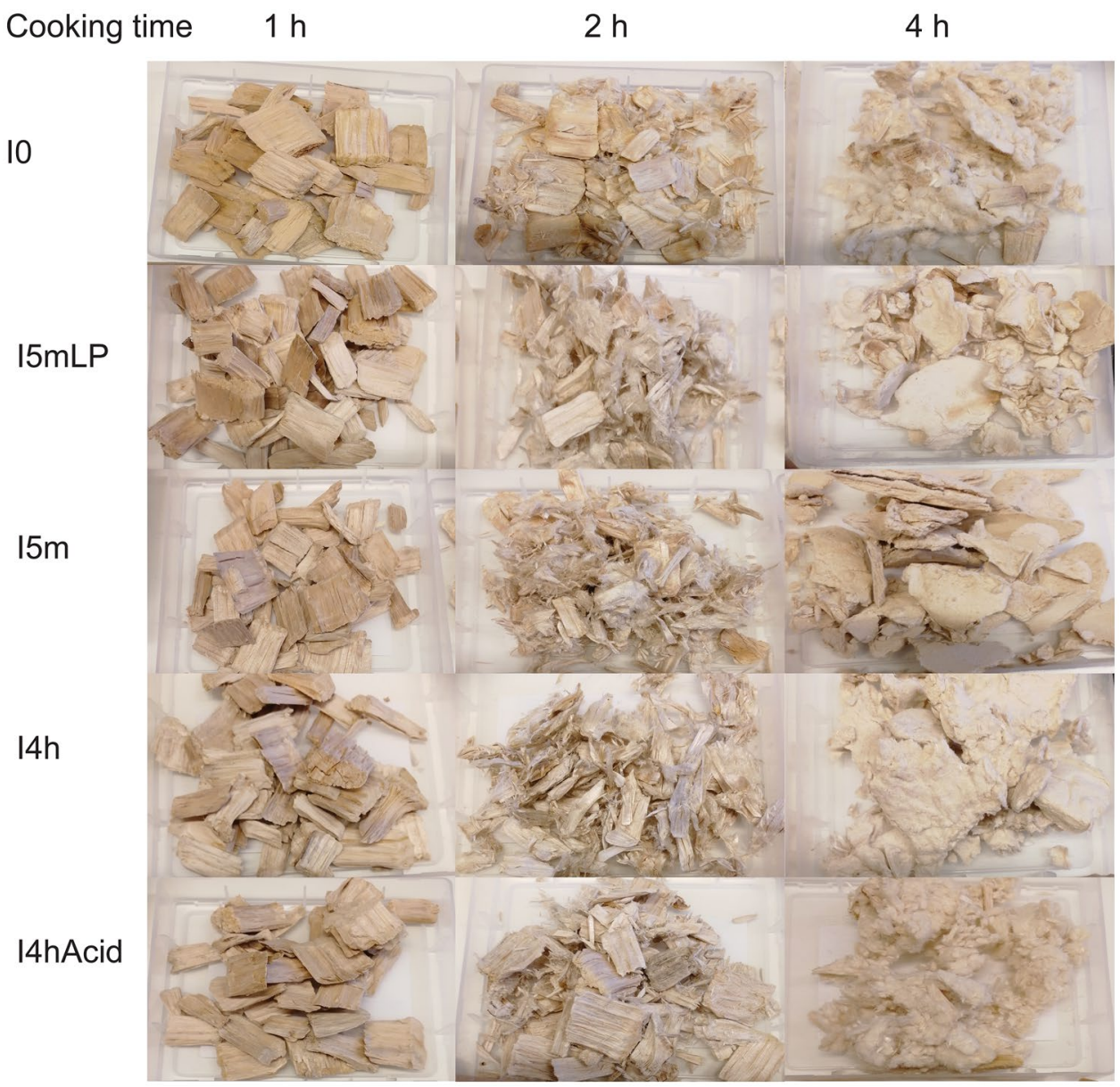

Compositional analysis of carbohydrates and lignin was done using two-step hydrolysis with sulfuric acid, essentially as described in the NREL/TP-510-42618 protocol [13]. Dry woody material (100 mg) was treated with $3 \mathrm{~mL}$ of $72 \%(\mathrm{w} / \mathrm{w})$ sulfuric acid at $30^{\circ} \mathrm{C}$ for one hour. Samples were diluted with deionized water to $4 \%(\mathrm{w} / \mathrm{w})$ sulfuric acid, and then autoclaved at $121^{\circ} \mathrm{C}$ for one hour. The samples were then filtered through Whatman glass microfiber filters (GE Healthcare, Buckinghamshire, UK) to separate the solid and the liquid fractions. The weight of the solid residue was measured after drying overnight at $105^{\circ} \mathrm{C}$ to estimate the Klason lignin content (triplicate samples). The filtrate was used to determine the content of monosaccharides (quadruplicate samples) and ASL (acid-soluble lignin) (triplicate samples). ASL was determined by measuring the absorbance at $240 \mathrm{~nm}$. Commonly occurring monosaccharides (glucose, mannose, xylose, galactose, and arabinose) were analyzed using HPAEC (high-performance anion-exchange chromatography). Specifically, an ICS-5000 system equipped with an electrochemical detector (Dionex, Sunnyvale, CA, USA) was used following the procedure described by Normark et al. [14].
Py-GC/MS was used to acquire further information about the chemical composition of the woody samples. Ball-milled fine wood powder (50-70 $\mu$ g) (quadruplicate samples) was applied to a pyrolyser (PY-2020iD and AS-1020E, Frontier Lab, Japan) connected to a GC-MS system (a 7890A/5975C series instrument from Agilent Technologies) and analyzed following the procedure described by Gerber et al. [15].

The ash content of dry wood powder $(100 \mu \mathrm{g})$ was analyzed following the procedure described in CEN/TS 14775:2004. The wood powder was added to a pre-weighed (w1) dry crucible. The crucible was heated to $550^{\circ} \mathrm{C}$ for a period of about two hours, and was then kept at that temperature for four hours. After cooling, the crucible and its content was weighed (w2). The difference in weight (w2-w1) was used to calculate the ash content of the sample.

\section{Results and discussion}

\subsection{Wood characteristics and chipping}

Wood chips from heartwood had significantly lower moisture content than wood chips from sapwood (Table 1). The 
difference was $17.8 \%$. Previous studies of various pine species have shown a similar trend, i.e. that sapwood has higher moisture content than heartwood [16].

The average wood chip thickness, according to the SCAN standard method, was $6.4 \mathrm{~mm}$ for heartwood and $5.3 \mathrm{~mm}$ for sapwood. It was clear that the wood chips from heartwood were significantly $(p \leq 0.01)$ thicker. Using the ScanChip analyzer the average thickness was $5.1 \mathrm{~mm}$ for heartwood and $4.2 \mathrm{~mm}$ for sapwood. The difference between the two methods depends on how the average thickness is determined, and the same trend (lower values for the ScanChip analyzer than for the SCAN standard method) has been observed also in earlier studies $[9,17]$. The trend that wood chips from heartwood were thicker than wood chips from sapwood was also supported by the thickness distribution data (Fig. 2b). There was a larger fraction of wood chips with thickness distribution 1.0-4.0 $\mathrm{mm}$ for sapwood than for heartwood. In agreement with that, there was a larger fraction of wood chips with thickness distribution 4.5-10 mm for heartwood than for sapwood.

According to the SCAN standard method, the fractions of oversized wood chips were almost the same (about 3\%) (Table 1). The ScanChip analyzer gave lower values: $1.6 \%$ for heartwood and $0.6 \%$ for sapwood. Oversized can be represented by just a few big pieces in the sample, and the difference between the two methods might be related to the sampling volume. The overthick fraction was significantly $(p \leq 0.01)$ larger for heartwood than for sapwood, and, according to both methods, heartwood wood chips contained a very large fraction (18.3-18.6\%) of overthick wood chips.

Regarding the accept fractions, there was a clear difference in the sense that a larger fraction of large accept was generated from heartwood, whereas, conversely, a larger fraction of small accept was generated from sapwood (Table 1). As a result, the fractions of total accept were similar, although a slightly larger fraction of total accept was generated from sapwood. These trends are supported by data from both the SCAN standard method and from the ScanChip analyzer (Table 1).

The fractions of pin chips and fines further supported the overall tendency that compared to heartwood more small-sized material was generated from sapwood (Table 1). The combined fractions of pin chips and fines determined using the SCAN method amounted to $6.9 \%$ for sapwood compared to only 3.2\% for heartwood. The results obtained with the ScanChip analyzer further underscore this difference, as the combined fraction of pin chips and fines amounted to $9.9 \%$ for sapwood and to $2.9 \%$ for heartwood.

The average values for length, width, and thickness, as determined using the ScanChip analyzer, are shown in Table 1, whereas the size distribution behind the average values is shown in Fig. 2. On an average, the wood chips from heartwood exhibited higher values than the wood chips from sapwood.

The fraction of material defined as wood chips by the ScanChip analyzer, i.e. the fraction referred to as "valid", ranged from $35.9 \%$ for sapwood to $55.1 \%$ for heartwood (Table 1). Pieces of wood that are not counted as valid can be too small or too large (smaller or larger than the intervals in Fig. 2), too uniform, or lack the cut edge that is needed to determine the difference between length and width. The difference between the fraction of valid wood pieces for heartwood and sapwood could potentially be due to the nature of the wood log parts, as sapwood from one wood log consisted of four parts that were thinner than the heartwood part. This would give more smallsized material and also more chips without a cut edge. As a

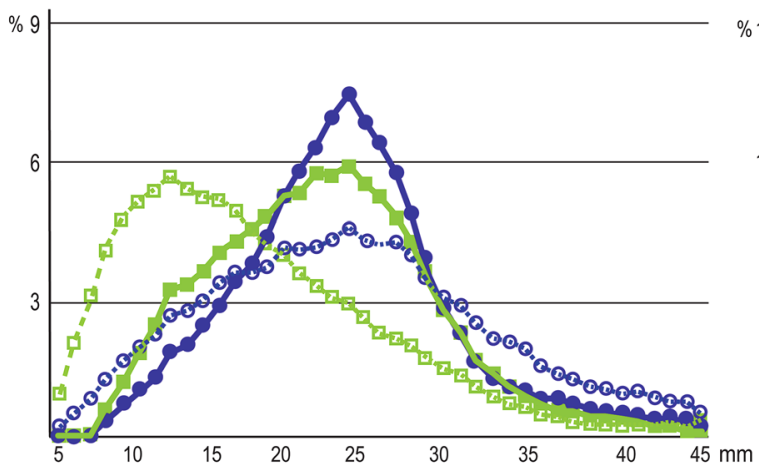

Fig. 2 Analysis of the size distribution of wood chips from heartwood or sapwood using the ScanChip analyzer. The figure shows the fractions of wood chips as a function of (a) length and width, and (b) thickness: heartwood, length and thickness, solid blue line, b

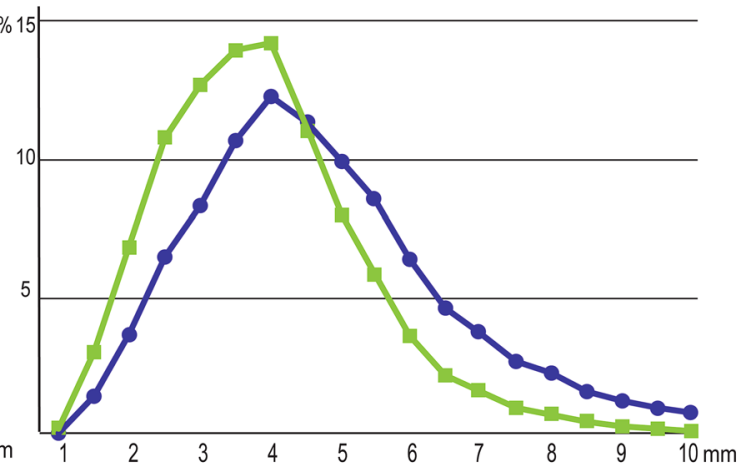

filled circles (O); heartwood, width, dashed blue line, open circles (O); sapwood, length and thickness, solid green line, filled squares ( $)$; sapwood, width, dashed green line, open squares $(\square)$ 
expected, the fraction of extractives and the content of pinosylvins (pinosylvin and pinosylvin monomethyl ether) were higher for heartwood than for sapwood (Table 1). The fraction of acetone extractives in heartwood was about three times higher than in sapwood. Similarly, the content of pinosylvins was about three times higher in heartwood (562 mg/kg) compared to sapwood ( $212 \mathrm{mg} / \mathrm{kg}$ ). The values are within the expected range for Scots pine, but the heartwood values are low compared to the contents found in many other wood samples [18].

The results of chemical analysis of the contents of carbohydrates and lignin in heartwood and sapwood are shown in Tables 3, 4. The abundance of the carbohydrates decreased in the order glucan $>$ mannan $>$ xylan $>$ galactan $>$ arabinan. This is as expected, as cellulose contributes to the glucan values, and as galactoglucomannan, glucomannan, and arabinoglucuronoxylan are common hemicelluloses in softwoods such as pine [5, 19]. While heartwood contained more glucan and mannan than sapwood, it contained slightly less xylan, galactan, and arabinan (Table 3). Results from compositional analysis (Table 3 ) and Py-GC/MS agree that heartwood contained $5-7 \%$ less carbohydrate than sapwood.

Compositional analysis showed higher values for Klason lignin and total lignin for heartwood compared to sapwood (Table 3), which is consistent with the results from the carbohydrate analysis. The values for ASL (Table 3 ) and lignin determined with Py-GC/MS (Table 4) did not show any larger differences. Higher values for Klason lignin and total lignin in heartwood compared to sapwood were reported also in a previous study of Scots pine [14]. As expected for softwood [20], the Py-GC/MS results (Table 4) suggest that the lignin consisted almost exclusively of guaiacyl units.

The ash content ranged from $0.2 \%$ for heartwood to $0.6 \%$ for sapwood. Values in the range $0.2-0.3 \%$ were previously reported for wood from Scots pine [14].

\subsection{Impregnation}

The absorption of impregnation liquid was clearly dependent on time and pressure (Table 2). Four hours impregnation at a pressure of 9 bar resulted in absorption of 0.92-1.0 kg of liquid, whereas five min impregnation at 9 bar resulted in absorption of $0.80 \mathrm{~kg}$ of liquid. When the pressure during impregnation was low (1-2 bar), the absorption of impregnation liquid after five min decreased to only $0.55 \mathrm{~kg}$. Thus, the results indicate that pressurized impregnation is a way to efficiently impregnate wood chips even at very short time periods. This is in agreement with previous findings that high moisture content, presteaming, and pressure impregnation facilitate impregnation [8].

SN Applied Sciences

\subsection{Sulfite cooking}

\subsubsection{Pulp yield}

The yields of pulp/woody material are indicated in Table 5 . However, as cooking for only one hour did not result in conversion of wood chips to pulp that was possible to screen, the analyses of reject (Table 5), pulp properties (Table 6), and fiber properties and fines (Table 7) were restricted to samples obtained after cooking for two or four hours.

The yield of pulp/woody material decreased with increased cooking time (Table 5). The yield ranges were: one hour cooking $67-73 \%$, two hours cooking $52-56 \%$, and four hours cooking $34-46 \%$. As the glucan content of heartwood was $34.5 \%$ DW (Table 3 ) and as the glucan fraction would be composed of not only cellulose but also of a fraction of some hemicelluloses, such as glucomannan and galactoglucomannan, most samples would be expected to contain not only cellulose, but at least some hemicelluloses and/or lignin. The yield was hardly affected by the impregnation time, but for each cooking time the low $\mathrm{pH}$ impregnation always resulted in the highest yield (Table 5).

\subsubsection{Reject}

The amount of reject was determined (Fig. 3 ) and the fraction of reject was calculated on basis of the initial amount of wood and pulp (Table 5). The fraction of reject was highly dependent on the inclusion of an impregnation step, the pressure during the impregnation step, and the cooking time (Table 5). In contrast, the impregnation time had very low or no impact on the fraction of reject, and the acidity of the impregnation liquid had only a small effect. Without any impregnation step, the fractions of reject on basis of pulp yield were very high: $26.5 \%$ for the two-hours cook and $7.9 \%$ for the four-hours cook. This indicates that is was hard for the cooking liquid to penetrate the wood chips without impregnation. Furthermore, impregnation at higher pressure was necessary to keep the fraction of reject low (Table 5). Thus, a pressurized impregnation step is a much better assurance of low levels of reject than a prolonged cooking time.

\subsubsection{Pulp properties}

The viscosity, the kappa number, and the ISO brightness of the screened pulp is shown in Table 6 . The viscosity was highly dependent on the cooking time (Table 6), and therefore also on the pulp yield (Table 5). For samples with two hours cooking time, the viscosity was rather similar and within the range $926-1004 \mathrm{~mL} \mathrm{~g}^{-1}$. 


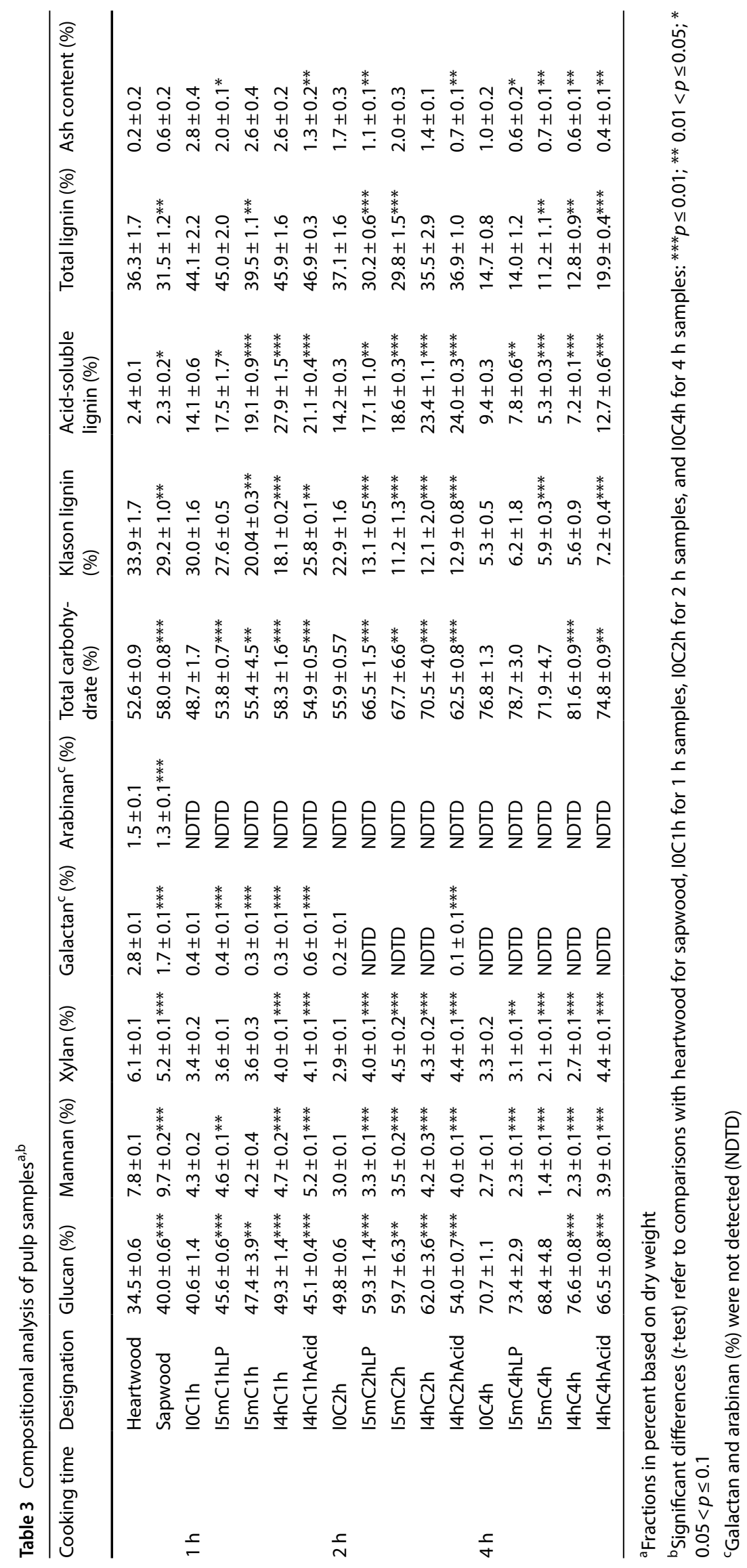


Table 4 Analysis of pulp samples using Py-GC/MS ${ }^{a, b}$

\begin{tabular}{|c|c|c|c|c|c|c|c|c|c|}
\hline $\begin{array}{l}\text { Cooking } \\
\text { time }\end{array}$ & $\begin{array}{l}\text { Designa- } \\
\text { tion }\end{array}$ & $\begin{array}{l}\text { Carbohy- } \\
\text { drate-related } \\
(\%)\end{array}$ & Guaiacyl (\%) & $\begin{array}{l}\text { Syringyl } \\
\text { (\%) }\end{array}$ & $\begin{array}{l}p \text {-Hydroxy- } \\
\text { phenyl (\%) }\end{array}$ & $\begin{array}{l}\text { Generic } \\
\text { benzene } \\
\text { derivatives }{ }^{c, d} \\
(\%)\end{array}$ & $\begin{array}{l}\text { Unknown } \\
\text { spectra (\%) }\end{array}$ & $\begin{array}{l}\text { Total lignin } \\
\text { (\%) }\end{array}$ & $C / L$ ratio $^{f}$ \\
\hline & $\begin{array}{l}\text { Heart- } \\
\text { wood }\end{array}$ & $63.3 \pm 0.9$ & $21.2 \pm 0.4$ & $0.8 \pm 0.2$ & $1.5 \pm 0.1$ & ND & $13.1 \pm 1.0$ & $23.5 \pm 0.2$ & $2.7 \pm 0.1$ \\
\hline & Sapwood & $70.4 \pm 0.5^{* * *}$ & $23.5 \pm 0.8^{* *}$ & $1.0 \pm 0.3$ & $0.4 \pm 0.1^{* * * *}$ & ND & $4.6 \pm 0.2^{* * *}$ & $24.9 \pm 0.5^{* *}$ & $2.8 \pm 0.1^{*}$ \\
\hline \multirow[t]{5}{*}{$1 \mathrm{~h}$} & $10 C 1 \mathrm{~h}$ & $64.7 \pm 0.6$ & $30.3 \pm 1.0$ & $0.1 \pm 0.1$ & $0.5 \pm 0.2$ & $0.1 \pm 0.1$ & $4.2 \pm 0.5$ & $31.1 \pm 1.0$ & $2.1 \pm 0.1$ \\
\hline & $15 \mathrm{mC} 1 \mathrm{hLP}$ & $65.4 \pm 1.2$ & $30.7 \pm 1.6$ & $<0.1^{*}$ & $2.0 \pm 0.4^{* * *}$ & NDTD & $1.9 \pm 0.3^{* * *}$ & $32.7 \pm 1.3^{*}$ & $2.0 \pm 0.2$ \\
\hline & $\mathrm{I} 5 \mathrm{mC} 1 \mathrm{~h}$ & $74.2 \pm 0.2^{* * *}$ & $23.3 \pm 0.3^{* * * *}$ & $<0.1^{*}$ & $0.9 \pm 0.1^{* * *}$ & NDTD & $1.6 \pm 0.3^{* * *}$ & $24.2 \pm 0.2^{* * * *}$ & $3.1 \pm 0.1^{* * *}$ \\
\hline & $14 \mathrm{hC} 1 \mathrm{~h}$ & $58.6 \pm 0.6^{* * *}$ & $29.8 \pm 0.7$ & $0.1 \pm 0.1$ & $3.1 \pm 0.2^{* * *}$ & NDTD & $8.4 \pm 0.8^{* * *}$ & $33.0 \pm 0.1^{* *}$ & $1.8 \pm 0.1^{* * *}$ \\
\hline & $\begin{array}{l}\text { I4hC1hA- } \\
\text { cid }\end{array}$ & $61.0 \pm 1.3^{* * *}$ & $26.8 \pm 0.8^{* * * *}$ & $0.2 \pm 0.1$ & $1.5 \pm 0.2^{* * *}$ & $1.1 \pm 0.2^{* * * *}$ & $9.4 \pm 1.7^{* * *}$ & $29.6 \pm 0.5^{* *}$ & $2.1 \pm 0.1$ \\
\hline \multirow[t]{5}{*}{$2 \mathrm{~h}$} & $10 C 2 \mathrm{~h}$ & $72.2 \pm 0.4$ & $21.1 \pm 0.5$ & $0.2 \pm 0.1$ & $0.7 \pm 0.2$ & $0.3 \pm 0.2$ & $5.6 \pm 0.1$ & $22.2 \pm 0.5$ & $3.3 \pm 0.1$ \\
\hline & $15 \mathrm{mC} 2 \mathrm{hLP}$ & $86.8 \pm 0.6^{* * *}$ & $10.0 \pm 0.7^{* * * *}$ & $<0.1^{* *}$ & $0.9 \pm 0.1^{* *}$ & NDTD & $2.3 \pm 0.2^{* * * *}$ & $10.9 \pm 0.8^{* * *}$ & $8.0 \pm 0.7^{* * *}$ \\
\hline & $15 \mathrm{mC} 2 \mathrm{~h}$ & $89.2 \pm 0.6^{* * * *}$ & $8.6 \pm 0.6^{* * *}$ & $<0.1^{* *}$ & $0.9 \pm 0.1$ & NDTD & $1.3 \pm 0.1^{* * * *}$ & $9.5 \pm 0.6^{* * *}$ & $9.4 \pm 0.7^{* * * *}$ \\
\hline & $14 \mathrm{hC} 2 \mathrm{~h}$ & $87.5 \pm 0.6^{* * *}$ & $9.6 \pm 0.5^{* * *}$ & $<0.1^{* *}$ & $1.0 \pm 0.1^{* *}$ & NDTD & $1.9 \pm 0.2^{* * * *}$ & $10.6 \pm 0.5^{* * *}$ & $8.3 \pm 0.5^{* * *}$ \\
\hline & $\begin{array}{l}\text { 14hC2hA- } \\
\text { cid }\end{array}$ & $72.3 \pm 0.6$ & $14.5 \pm 0.6^{* * *}$ & $0.3 \pm 0.1^{*}$ & $2.0 \pm 0.3^{* * * *}$ & $1.7 \pm 0.1^{* * *}$ & $9.4 \pm 0.4^{* * *}$ & $18.3 \pm 0.7^{* * *}$ & $4.0 \pm 0.2^{* * * *}$ \\
\hline \multirow[t]{5}{*}{$4 \mathrm{~h}$} & $10 C 4 \mathrm{~h}$ & $92.9 \pm 0.4$ & $0.9 \pm 0.2$ & $0.2 \pm 0.1$ & $0.2 \pm 0.1$ & $0.2 \pm 0.1$ & $5.7 \pm 0.3$ & $1.5 \pm 0.3$ & $64 \pm 10$ \\
\hline & $15 \mathrm{mC} 4 \mathrm{hLP}$ & $88.0 \pm 1.4^{* * *}$ & $0.1 \pm 0.1^{* * *}$ & $0.1 \pm 0.1^{*}$ & $0.2 \pm 0.1^{* * * *}$ & NDTD & $11.8 \pm 1.3^{* * *}$ & $0.3 \pm 0.1^{* * *}$ & $270 \pm 30^{* *}$ \\
\hline & $15 \mathrm{mC} 4 \mathrm{~h}$ & $87.2 \pm 5.9$ & $0.1 \pm 0.1^{* * * *}$ & $<0.1^{*}$ & $<0.1^{* * *}$ & NDTD & $12.6 \pm 5.8^{*}$ & $0.2 \pm 0.1^{* * *}$ & $480 \pm 140 * * *$ \\
\hline & I4hC4h & $87.6 \pm 3.5^{*}$ & $0.1 \pm 0.1^{* * *}$ & $0.1 \pm 0.1^{*}$ & $<0.1^{* * *}$ & NDTD & $12.2 \pm 3.5^{* *}$ & $0.2 \pm 0.1^{* * *}$ & $510 \pm 140^{* * * *}$ \\
\hline & $\begin{array}{l}\text { I4hC4hA- } \\
\text { cid }\end{array}$ & $92.5 \pm 0.8$ & $1.3 \pm 0.2^{* *}$ & $0.2 \pm 0.1$ & $0.2 \pm 0.1^{* *}$ & $0.1 \pm 0.1^{*}$ & $5.8 \pm 0.9$ & $1.7 \pm 0.2^{* * *}$ & $53 \pm 4$ \\
\hline
\end{tabular}

${ }^{\mathrm{a}}$ Fractions in percent based on dry weight (calculated as fractions of the total signals of carbohydrate, guaiacyl, syringyl, $p$-hydroxyphenyl, generic benzene derivatives, and unknown)

${ }^{\mathrm{b}}$ Significant differences (t-test) refer to comparisons with heartwood for sapwood, $10 \mathrm{C} 1 \mathrm{~h}$ for $1 \mathrm{~h}$ samples, $10 \mathrm{C} 2 \mathrm{~h}$ for $2 \mathrm{~h}$ samples, and $10 \mathrm{C} 4 \mathrm{~h}$ for $4 \mathrm{~h}$ samples: ${ }^{* * *} p \leq 0.01 ;{ }^{* *} 0.01<p \leq 0.05 ;{ }^{*} 0.05<p \leq 0.1$

'The fraction of generic benzene derivatives (\%) was not detected (NDTD) or not determined (ND)

${ }^{\mathrm{d}}$ Generic benzene derivatives (without hydroxyl group on aromatic ring) most probably originated from lignin

${ }^{\mathrm{e}}$ Total lignin is the sum of guaiacyl, syringyl, $p$-hydroxyphenyl and generic benzene derivatives

${ }^{f}$ Carbohydrate/lignin ratio

With four hours cooking time, the viscosity was reduced to $409-964 \mathrm{~mL} \mathrm{~g}^{-1}$. The highest viscosity values for four hours cooking samples were $964 \mathrm{~mL} \mathrm{~g}^{-1}$ for $14 \mathrm{hC} 4 \mathrm{hAcid}$ and $718 \mathrm{~mL} \mathrm{~g}^{-1}$ for $10 \mathrm{C} 4 \mathrm{~h}$, whereas it was below $540 \mathrm{~mL} \mathrm{~g}^{-1}$ for the others. Thus, the inclusion of an impregnation step and the acidity of the impregnation liquid had a large impact on the viscosity after prolonged cooking.

The link between pulp yield and viscosity is a wellknown phenomenon. Sulfite pulp from spruce had a viscosity of $200 \mathrm{~mL} \mathrm{~g}^{-1}$ when the yield was around $39 \%$, $350-700 \mathrm{~mL} \mathrm{~g}^{-1}$ when the yield was around $45 \%$, and $800-1000 \mathrm{~mL} \mathrm{~g}^{-1}$ when the yield was around $46-47 \%$ [8].

After cooking for two or four hours, the kappa number ranged from 65 down to around 10 (Table 6). The decrease in kappa number, which should reflect the decrease in lignin content during pulping, was highly dependent on the cooking time, the inclusion of an impregnation step, pressurized impregnation, and the acidity of the impregnation liquid. Provided that the impregnation was pressurized and the impregnation liquid had the right $\mathrm{pH}$, it did not matter if the impregnation time was five min or four hours (Table 6). The impregnation step had such a large effect that the kappa number after two hours of cooking for pressurized impregnation with normal impregnation liquid (36-38) was lower than the kappa number after four hours of cooking without any impregnation step ( 45).

The ISO brightness varied from around $57 \%$ up to around $74 \%$ (Table 6). The values after four hours of cooking were typically higher than the corresponding values after two hours of cooking, which could also be observed visually by looking at the paper sheets (Fig. 4). The impregnation with low pressure consistently resulted in the lowest values for ISO brightness. The result further points at the importance of having a pressurized impregnation step. 
Table 5 Pulp screening results

\begin{tabular}{lllllll}
\hline Cooking time & Designation & Pulp yield (g) & $\begin{array}{l}\text { Pulp yield } \\
\left(\mathrm{g} \mathrm{g}^{-1}\right)\end{array}$ & Reject (g) & $\begin{array}{l}\text { Reject_raw } \\
\text { material }^{\mathrm{b}}(\%)\end{array}$ & $\begin{array}{l}\text { Reject- } \\
\text { pulp }^{\mathrm{c}} \\
(\%)\end{array}$ \\
\hline $1 \mathrm{~h}^{\mathrm{d}}$ & IOC1h & 54.6 & 0.68 & NDTD & ND & ND \\
& I5mC1hLP & 56.3 & 0.70 & NDTD & ND & ND \\
& I5mC1h & 54.8 & 0.68 & NDTD & ND & ND \\
& I4hC1h & 53.5 & 0.67 & NDTD & ND & ND \\
& I4hC1hAcid & 58.1 & 0.73 & NDTD & ND & ND \\
& IOC2h & 43.3 & 0.54 & 11.4 & 14.3 & 26.5 \\
& I5mC2hLP & 41.7 & 0.52 & 3.96 & 5.0 & 9.5 \\
& I5mC2h & 42.0 & 0.52 & 0.12 & 0.2 & 0.3 \\
& I4hC2h & 41.5 & 0.52 & 0.17 & 0.2 & 0.4 \\
& I4hC2hAcid & 45.0 & 0.56 & 0.82 & 1.0 & 1.8 \\
& I0C4h & 34.9 & 0.44 & 2.76 & 3.5 & 7.9 \\
& I5mC4hLP & 31.9 & 0.40 & 1.45 & 1.8 & 4.6 \\
& I5mC4h & 27.3 & 0.34 & 0.04 & $<0.1$ & 0.2 \\
& I4C4h & 29.2 & 0.36 & 0.03 & $<0.1$ & 0.10 \\
& I4hC4hAcid & 36.6 & 0.46 & 0.06 & $<0.1$ & 0.2 \\
\hline
\end{tabular}

${ }^{\text {a }}$ Yield in $\mathrm{g}$ divided by the dry weight of the added wood chips $(80 \mathrm{~g})$

${ }^{\mathrm{b}}$ Reject in $\mathrm{g}$ divided by the dry weight of the added wood chips $(80 \mathrm{~g})$ (fraction of reject based on raw material)

${ }^{\mathrm{C}}$ Reject in $\mathrm{g}$ divided by pulp yield in $\mathrm{g}$ (fraction of reject based on pulp)

${ }^{\mathrm{d}}$ The woody material was still in the form of wood chips and no pulp could be extracted. Values could therefore not be detected (NDTD) or not be determined (ND)

Table 6 Pulp properties ${ }^{\mathrm{a}, \mathrm{b}}$

\begin{tabular}{llccl}
\hline Cooking time & Designation & Viscosity $\left(\mathrm{mL} \mathrm{g}^{-1}\right)$ & Kappa number & ISO brightness (\%) \\
\hline $2 \mathrm{~h}$ & I0C2h & $926 \pm 24$ & $65.2 \pm 7.3$ & $62.7 \pm 0.1$ \\
& I5mC2hLP & $933 \pm 6$ & $60.4 \pm 1.1$ & $56.9 \pm 0.0^{* * *}$ \\
& I5mC2h & $965 \pm 9^{*}$ & $36.0 \pm 0.6^{* *}$ & $63.8 \pm 0.1^{* * *}$ \\
& I4hC2h & $1004 \pm 17^{* *}$ & $38.1 \pm 3.4^{* *}$ & $63.1 \pm 0.2^{* *}$ \\
& I4hC2hAcid & $1001 \pm 13^{* *}$ & $60.2 \pm 6.3$ & $63.4 \pm 0.1^{* * *}$ \\
& I0C4h & $718 \pm 4$ & $44.8 \pm 0.6$ & $73.6 \pm 0.1$ \\
& I5mC4hLP & $538 \pm 2^{* * *}$ & $29.6 \pm 2.8^{* * *}$ & $58.8 \pm 0.1^{* * *}$ \\
& I5mC4h & $409 \pm 3^{* * *}$ & $10.6 \pm 0.1^{* * *}$ & $61.6 \pm 0.2^{* * *}$ \\
& I4hC4h & $537 \pm 2^{* * *}$ & $9.7 \pm 0.2^{* * *}$ & $68.8 \pm 0.1^{* * *}$ \\
& I4hC4hAcid & $964 \pm 7^{* * *}$ & $18.9 \pm 0.6^{* * *}$ & $73.9 \pm 0.1^{* * *}$
\end{tabular}

a Values for pulp quality using ISO 302:2004, ISO 5351:2010, and ISO 2470-1:2016

${ }^{b}$ Significant differences ( $t$-test) refer to comparisons with $10 \mathrm{C} 2 \mathrm{~h}$ for $2 \mathrm{~h}$ samples and with $10 \mathrm{C} 4 \mathrm{~h}$ for $4 \mathrm{~h}$ samples: ${ }^{* *} p \leq 0.01 ;{ }^{* *} 0.01<p \leq 0.05 ;{ }^{*} 0.05<p \leq 0.1$

The fiber length typically decreased with increasing cooking time, except for the samples from low-pressure impregnation and impregnation with cooking liquid (Table 7). The fiber length values for samples from pressurized impregnation using normal impregnation liquid were similar for a given cooking time, regardless of whether the impregnation time was five min or four hours. The fiber width and the fiber curl were typically not affected by the cooking time (Table 7).
The content of fines increased with increasing cooking time, except for the pulps from low-pressure impregnation and impregnation with cooking liquid. Thus, the pattern for content of fines followed the pattern of the fiber length measurements. As fines are created by fragmentation of fibers, it is expected that there is a strong link between the content of fines and the average fiber length. A fines content as high as $21.9-36.3 \%$ indicates that the cooking conditions were too harsh. The values 
Table 7 Fiber properties and fines ${ }^{\mathrm{a}}$

\begin{tabular}{lllllll}
\hline Cooking time & Designation & $\begin{array}{l}\text { Fiber } \\
\text { length } \\
(\mathrm{mm})\end{array}$ & $\begin{array}{l}\text { Fiber } \\
\text { width } \\
(\mathrm{mm})\end{array}$ & Fiber curl (\%) & Fines (\%) & $\begin{array}{l}\text { Fiber coarse- } \\
\text { ness (mg/m) }\end{array}$ \\
\hline $2 \mathrm{~h}$ & I0C2h & 1.3 & 28 & 18.6 & 10.2 & 0.19 \\
& I5mC2hLP & 1.6 & 28 & 14.1 & 7.6 & 0.13 \\
& I5mC2h & 1.6 & 27 & 16.2 & 7.0 & 0.16 \\
& I4hC2h & 1.6 & 28 & 18.2 & 5.9 & 0.20 \\
& I4hC2hAcid & 1.7 & 29 & 14.1 & 7.4 & 0.16 \\
& I50C4h & 1.0 & 28 & 18.7 & 25.2 & 0.23 \\
& I5mC4hLP & 1.6 & 28 & 14.1 & 7.6 & 0.13 \\
& I5mC4h & 0.7 & 29 & 16.7 & 36.3 & 0.26 \\
& I4C4h & 0.8 & 28 & 18.8 & 21.9 & 0.23 \\
& I4hC4hAcid & 1.6 & 29 & 16.3 & 8.3 & 0.19 \\
\hline
\end{tabular}

${ }^{a}$ Values for pulp quality determined using ISO 16,065-2 (fiber length), Fa 10.400, and Fa 10.401

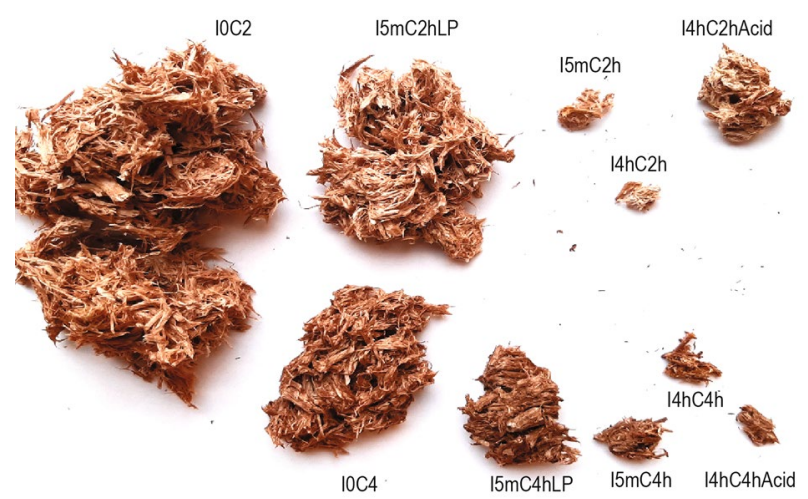

Fig. 3 Images of reject fractions

for fiber coarseness typically increased with increasing cooking time, except for the pulp from low-pressure impregnation. The same trend, i.e. higher fines content when the fiber length decreased, was detected in studies of bleached sulfite pulp [21], although the fines content for the bleached pulp was in the range 55.8-92.6\%.

\subsection{Chemical composition}

Analyses of pulp screening, pulp properties, and fiber properties (Tables 5-7) were complemented with compositional analysis (Table 3) and Py-GC/MS analysis (Table 4) to obtain a more detailed view of the chemical effects of the impregnation and cooking conditions. As expected, compositional analysis (Table 3 ) showed increased glucan content, primarily reflecting increased cellulose content, with increased cooking time. The glucan content increased from around $34 \%$ for heartwood to $41-49 \%$ for one hour cooking time, $50-62 \%$ for two hours, and $66-77 \%$ for four hours. For one and two hours of cooking, the lowest glucan and total carbohydrate values were obtained

Fig. 4 Images of pulp sheets

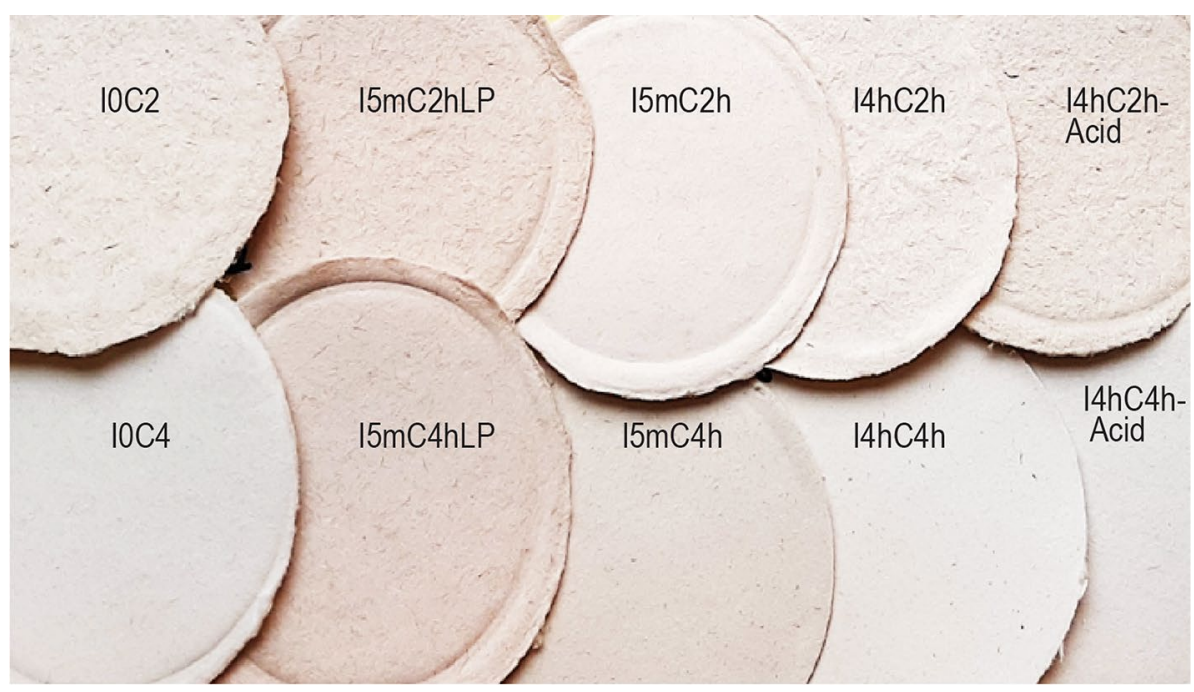


for the wood that was not impregnated (I0C1h, $10 \mathrm{C} 2 \mathrm{~h}$ ). The highest glucan and total carbohydrate values for a given cooking time were always observed for wood that was impregnated for the longest time period using high pressure and normal impregnation liquid $(14 \mathrm{hC} 1 \mathrm{~h}, 14 \mathrm{hC} 2 \mathrm{~h}$, $14 \mathrm{hC} 4 \mathrm{~h})$. In contrast to glucan, the fractions of hemicellulosic carbohydrates (i.e. mannan, xylan, galactan, and arabinan) always decreased after cooking (Table 3). From the beginning (heartwood), the fraction of hemicellulosic carbohydrates out of total carbohydrates was $35 \%$. After impregnation for four hours using high pressure and normal impregnation liquid and cooking, that fraction decreased to $15 \%$ (I4hC1h), 12\% (I4hC2h), and $6 \%$ (14hC4h). Thus, the decrease in hemicellulosic carbohydrates was rapid during the first hour of cooking, after which it decreased steadily at a slower rate. Preferential degradation of hemicelluloses is in agreement with earlier literature. Compared to cellulose, hemicelluloses are less structured and have a lower degree of polymerization, and are therefore removed during bisulfite cooking [5, 22]. In a study of bisulfite cooking of spruce wood, the fraction of xylan decreased from around 5\% to 3\% after five hours of cooking. The fraction of glucomannan decreased from around $11 \%$ to $7-8 \%$ after $5 \mathrm{~h}$, and similar results were obtained with pine wood $[23,24]$.

The effects of impregnation and cooking on the fraction of lignin were studied by compositional analysis (Klason lignin and ASL in Table 3) and Py-GC/MS (Table 4). The values can be compared to the kappa numbers in Table 6 .

After one hour of cooking, the fractions of total lignin had increased slightly or were similar to the starting material (Tables 3,4). This is also reflected by the $C / L$ (carbohydrate/lignin) ratio (Table 4). That effect can be attributed to the rapid initial degradation of hemicellulosic carbohydrates. However, the values for Klason lignin and ASL reveal further details (Table 3). After one hour of cooking, all samples exhibited decreased Klason lignin content and increased ASL content. This effect was most pronounced for $14 \mathrm{hC} 1 \mathrm{~h}$, and least pronounced for $10 \mathrm{C} 1 \mathrm{~h}$, which indicates that inclusion of an impregnation step, particularly at high pressure and using normal impregnation liquid, promoted partial degradation of lignin resulting in conversion of Klason lignin to ASL.

After two hours of cooking, the total lignin values were similar to or lower than those of the starting material (Tables 3, 4). As most hemicellulosic carbohydrates had been lost at this stage, these values reflect that a substantial fraction of the lignin was washed out from the pulps. The Klason lignin values had decreased both compared to the starting material and compared to the values after one hour of cooking (Table 3). Removal of lignin was lagging behind especially for $10 \mathrm{C} 2 \mathrm{~h}$, as shown by values for total lignin, kappa number, and, particularly, Klason lignin.
After four hours of cooking, most of the lignin had been removed in all samples, at least according to Klason lignin determination (Table 3) and Py-GC/MS analysis (Table 4). The kappa number results (Table 6), which pointed towards $10 \mathrm{C} 4 \mathrm{~h}, 15 \mathrm{mC} 4 \mathrm{hLP}$, and $14 \mathrm{hC} 4 \mathrm{hAcid}$ containing substantially more lignin than $15 \mathrm{mC} 4 \mathrm{~h}$ and $14 \mathrm{hC} 4 \mathrm{~h}$, agreed to some extent with the total lignin as determined with compositional analysis (Table 3), whereas it was more difficult to discern the same pattern in the results from Py-GC/ MS (Table 4). Sulfonation of lignin is likely to have caused some problems with the Py-GC/MS analysis, which was not adapted to detection of sulfonated lignin-degradation products. The conversion of Klason lignin (acid-insoluble lignin) to ASL would be an effect of both fragmentation and sulfonation. Sulfonation results in hydrophilization, which facilitates solubilisation. While more research is needed to further elucidate the reasons why the lignin analysis methods sometimes differed from each other, the results agree in the sense that the inclusion of a pressurized impregnation step and using normal impregnation liquid rather than more acidic were important measures for achieving efficient lignin removal.

The ash content first increased compared to the starting material (heartwood), and then gradually decreased with increasing cooking time (Table 3). The lowest values within each cooking time were observed for the most acidic impregnation reaction. The increase in ash content after impregnation and cooking can be explained, at least in part, by sulfonation of lignin. The negatively charged groups will attract cations, such as sodium (the counter ion of the cooking liquid), potassium, and calcium, and salts will result in ash. When the cooking time increased, the fraction of sulfonated lignin in the solids would decrease, and so would formation of ash. The sulfonation reactions might have been less efficient for the most acidic reaction, which would have resulted in relatively poor delignification, less salts, and less ash.

\section{Conclusions}

The investigation showed clear advantages with the inclusion of a pressurized impregnation step prior to sulfite cooking of heartwood of pine. It also showed that the duration of the impregnation step was not critical, as results obtained with five min impregnation were often similar to results obtained with a four-hours impregnation step. As the approach was generally successful, it would be interesting to investigate impregnation conditions with varied pressure and temperature in the future. The raw material had relatively low content of pinosylvins and cooking was performed with a relatively high liquid-towood ratio. In future studies it would be of interest to also include wood with higher content of pinosylvins, utilize a 
lower liquid-to-wood ratio in the cooking step, and compare the impregnation rates in sapwood and heartwood.

Acknowledgements We are grateful to Sten Häggström, Multi Channel Sweden $A B$, for the supply of wood, for debarking and preparation of wood logs, and for help with wood chipping. We also want to thank Domsjö Fabriker AB for access to their wood yard, and Metsä Board Husum for access to their ScanChip analyzer. The services of Junko Takahashi-Schmidt at the Biopolymer Analytical Facility of the KBC Chemical-Biological Center in Umeå are gratefully acknowledged. We are grateful for the support from the Kempe Foundations, the Swedish Energy Agency, RISE Processum AB, the Industrial Doctoral School of Umeå University, and the strategic research environment Bio4Energy.

Funding Open access funding provided by Umeå University, Kempe Foundations, the Swedish Energy Agency, RISE Processum AB, the Industrial Doctoral School of Umeå University, and the strategic research environment Bio4Energy.

Data availability Most materials were consumed or discarded after analysis. Sheets for light measurements and analysis data were kept by the corresponding author.

Code availability Standard software was used (Microsoft, Adobe).

\section{Compliance with ethical standards}

Conflicts of interest The authors declare that they have no conflict of interest.

Open Access This article is licensed under a Creative Commons Attribution 4.0 International License, which permits use, sharing, adaptation, distribution and reproduction in any medium or format, as long as you give appropriate credit to the original author(s) and the source, provide a link to the Creative Commons licence, and indicate if changes were made. The images or other third party material in this article are included in the article's Creative Commons licence, unless indicated otherwise in a credit line to the material. If material is not included in the article's Creative Commons licence and your intended use is not permitted by statutory regulation or exceeds the permitted use, you will need to obtain permission directly from the copyright holder. To view a copy of this licence, visit http://creativecommons.org/licenses/by/4.0/.

\section{References}

1. Patrick K (2011) Dissolving pulp gold rush in high gear. Paper $3606: 8-12$

2. Sixta $H$, lakovlev $M$, Testova $L$, Roselli $A$, Hummel $M$, Borrega M, Schottenberger H (2013) Novel concepts of dissolving pulp production. Cellulose 20:1547-1561. https://doi.org/10.1007/ s10570-013-9943-1

3. Sixta H, Harms H, Dapia S et al (2004) Evaluation of new organosolv dissolving pulps. Part I: preparation, analytical characterization and viscose processability. Cellulose 11:73-83. https://doi. org/10.1023/B:CELL.0000014767.47330.90

4. Ek M, Gellerstedt G, Henriksson G (2009) Pulp and paper chemistry and technology, vol 2. Pulping Chemistry and Technology, De Gruyter, Berlin

5. Sjöström E (1993) Wood chemistry-fundamentals and applications, 2nd edn. Academic Press, San Diego, CA

6. Hanhikoski S, Warsta E, Varhimo A et al (2016) Sodium sulphite pulping of Scots pine under neutral and mildly alkaline conditions (NS pulping). Holzforschung 70:603-609. https://doi. org/10.1515/hf-2015-0099

7. Skogsdata (2019) Sveriges officiella statistik. Institutionen för skoglig resurshushållning, SLU, Umeå

8. Sixta H (2006) Handbook of pulp. Wiley-VCH, Weinheim

9. Gard Timmerfors J, Jönsson LJ (2019) Evaluation of novel drum chipper technology: pilot scale production of short wood chips. TAPPI J 18: 585-592 10.32964/TJ18.10.585

10. Gandla ML, Derba-Maceluch M, Gerber LX, L, Master ER, Mellerowicz EJ, Jönsson LJ, (2015) Expression of a fungal glucuronoyl esterase in populus: effects on wood properties and saccharification efficiency. Phytochemistry 112:210-220. https://doi. org/10.1016/j.phytochem.2014.06.002

11. Malkov S, Tikka P, Gullichsen J (2001) Towards complete impregnation of wood chips with aqueous solutions. Part 2. Studies on water penetration into softwood chips. Pap Puu-Pap Tim 84:526-530

12. Määttänen $M$, Tikka $P(2008)$ Penetration of water into industrial softwood chips-influence of physical properties. Pap Puu-Pap Tim 90:41-46

13. Sluiter A, Hames B, Ruiz R, et al. (2012) Determination of structural carbohydrates and lignin in biomass. NREL/TP-510-42618, National Renewable Energy Laboratory, Golden, CO.

14. Normark M, Winestrand S, Lestander TA, Jönsson LJ (2014) Analysis, pretreatment and enzymatic saccharification of different fractions of Scots pine. BMC Biotechnol 1:20. https://doi. org/10.1186/1472-6750-14-20

15. Gerber L, Eliasson M, Trygg J, Moritz T, Sundberg B (2012) Multivariate curve resolution provides a high-throughput data processing pipeline for pyrolysis gas chromatography/mass spectrometry. J Anal Appl Pyrol 9:95-100. https://doi.org/10.1016/j. jaap.2012.01.011

16. Rowell RM (2013) Handbook of wood chemistry and wood composites. CRC Press, Boca Raton, FL

17. Gard Timmerfors J, Sjölund T, Jönsson LJ (2020) New drum-chipping technology for a more uniform size distribution of wood chips. Holzforschung 74:116-122. https://doi.org/10.1515/ hf-2018-0279

18. Willför S, Hemming J, Reunanen M, Holmbom B (2003) Phenolic and lipophilic extractives in Scots pine knots and stemwood. Holzforschung 57:359-372. https://doi.org/10.1515/HF.2003.054

19. Donev E, Gandla ML, Jönsson LJ, Mellerowicz E (2018) Engineering non-cellulosic polysaccharides of wood for the biorefinery. Front Plant Sci 9:1537. https://doi.org/10.3389/fpls.2018.01537

20. Ralph J, Lapierre C, Boerjan W (2019) Lignin structure and its engineering. Curr Opin Biotechnol 56:240-249. https://doi. org/10.1016/j.copbio.2019.02.019

21. Sundman O, Albán Reyes DC, Svedberg A, Hellström S (2016) On the origin of the spectroscopic signals of cellulose ll-type in sulphite dissolving pulp. Nord Pulp Pap Res J 31:54-60. https:// doi.org/10.3183/npprj-2016-31-01-p054-060

22. Rydholm SA (1965) Pulping processses. Krieger Publishing Company, Malabar, FL

23. Deshpande R, Sundvall L, Grundberg H, Germgård U (2016) The influence of different types of bisulfite cooking liquors on pinewood components. BioResources 11:5961-5973. https://doi. org/10.15376/biores.11.3.5961-5973

24. Deshpande R, Giummarella N, Henriksson G, Germgård U, Sundvall L, Grundberg H, Lawoko M (2018) The reactivity of lignin carbohydrate complex (LCC) during manufacture of dissolving sulfite pulp from softwood. Ind Crop Prod 115:315-322. https ://doi.org/10.1016/j.indcrop.2018.02.038

Publisher's Note Springer Nature remains neutral with regard to jurisdictional claims in published maps and institutional affiliations. 